\title{
Coastal Sea Salt Chlorine Deposition Linked to Intertropical Convergence Zone (ITCZ) Oscillation in French Guiana
}

\author{
M. L. GOBINDDASS \\ UMR Espace DEV, Univ. Montpellier, IRD, Univ. Antilles, Univ. Guyane, Univ. Réunion, Montpellier, and \\ UMR Espace DEV, Univ. Guyane, Univ. Montpellier, IRD, Univ. Antilles, Univ. Réunion, Cayenne, France
}

\section{J. MOLINIE}

Laboratory of Research in Geosciences and Energies, University of Antilles, Campus de Fouillole, Pointe-à-Pitre, Guadeloupe

\section{S. RICHARD}

Centre National d'Etude Spatiale, Kourou, French Guiana

\author{
K. Panechou, A. Jeannot, and S. Jean-Louis \\ Atmo Guyane Degrad des Cannes, Remire-Montjoly, French Guiana
}

(Manuscript received 22 February 2019, in final form 25 February 2020)

\begin{abstract}
Sea salt chloride is a major component of atmospheric aerosol and its behavior is an essential element in determining the climate. Two atmospheric chlorine deposition measurement procedures were performed between 2004 and 2008 by the French Guiana Regional Air Observatory (ORA), in the coastal plain of Sinnamary. The main goal was to determine the background spatial distribution of marine chlorine in order to evaluate the impact of Ariane rocket hydrogen chloride emission. To determine the chlorine concentration level, weekly samples from 10 sites were analyzed. A seasonal pattern was identified. For every site, a high sea salt chlorine deposition level was observed from December to April and a low level from July to October. The ratio of high to low mean chloride concentration $R_{\mathrm{HC} / \mathrm{LC}}$ shows that just under half of the variation in chlorine deposition can be linked to the variation of sea salt production with low-level wind speed. Equations relating mean sea salt chlorine concentration and the distance to shore were studied, taking into account parameters found in other tropical regions, with a focus on neighboring Brazil. The wind rotation between the two seasons, and the sea salt chlorine

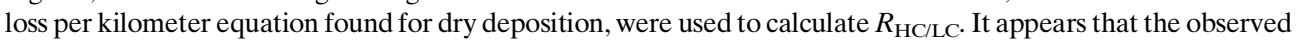
rotation $\left(60^{\circ}\right)$ explains $88 \%$ of $R_{\mathrm{HC} / \mathrm{LC}}$. Finally, inland sea salt chlorine deposition behavior in this region was linked to intertropical convergence zone oscillation through variations in wind speed and direction.
\end{abstract}

\section{Introduction}

Sea salts play an important role in cloud production processes and, consequently, in Earth's climate. Chlorine deposition has therefore been studied on large geographical and temporal scales. In coastal regions, salt deposition is responsible for the degradation and corrosion of metallic structures. Additionally, it is an important ecological factor because of the influence of salinity on plants and animals. In coastal regions, the

Corresponding author: M. L. Gobinddass, marieline.gobinddass@ gmail.com established distribution of marine aerosols shows a decrease in sea salt amount going inland from the coast. Over ocean, wind stress leads to the existence of whitecaps and waves, and interactions between these, or with the shore, produce spray and marine aerosols. Above ocean and coastal areas, most droplets are produced by breaking waves (Gustafsson and Franzén 1996; de Leeuw et al. 2011). If the relative humidity is below $75 \%$, most of the liquid aerosols crystallize.

In some areas of the planet, wind regimes can vary strongly (in speed and orientation), depending on the season, leading to a seasonality in sea salt chlorine production and deposition (Tsunogai 1975; Ambler and 
Bain 1955; Corvo et al. 1995; Gustafsson and Franzén 1996; Meira et al. 2003, 2006; Hossain and Easa 2011). Indeed, the number of marine particles (salt concentration) increases with increasing wind speed (Pruppacher and Klett 1980; McDonald et al. 1982; Monahan et al. 1983; Gong 2003; Vignati et al. 2010). As a result, salt concentration $C$ over ocean or near the shore increases exponentially with wind speed $u\left(\mathrm{~m} \mathrm{~s}^{-1}\right)$ :

$$
C=a e^{b u}
$$

where $a$ and $b$ are parameters that vary with region

A review of numerous studies, with values of $a$ and $b$ values for different regions around the world, is given by Meira et al. (2003).

Gravity causes the heaviest particles to remain along the coast, while the smaller ones are transported very far inland (Gustafsson and Franzén 1996). Several laws, using power or exponential functions, have been used to model the relationship between salt concentration and distance from the coast (Meira et al. 2003, 2006, 2007). On the tropical Atlantic coast of South America, moisture is important and nearly constant throughout the year (Andreae et al. 1986; Meira et al. 2006, 2007). Wet deposition accounts for half of the total deposition and is generally observed to occur over the ocean (Erikson and Duce 1988). The climate of the experimental area, situated near $5^{\circ} \mathrm{N}$, is influenced by the intertropical convergence zone (ITCZ), which over the Atlantic Ocean is driven by the Azores and Saint Helen high pressures. In this location, there are two main seasons, the dry season when the ITCZ is located at latitudes higher or equal to $10^{\circ} \mathrm{N}$, and the rainy season when it cycles between $5^{\circ} \mathrm{S}$ and $6^{\circ} \mathrm{N}$. During the rainy season, from November to June, when the ITCZ is located at its most southerly position $\left(5^{\circ} \mathrm{S}\right)$, a short dry period occurs, called the "small summer of March" (Héritier 2011).

In addition, for the Guiana basin (French Guiana, Surinam, Guyana), the oscillation of the ITCZ produces a seasonality in wind direction in the lower layers of the atmosphere (Molinié and Pontikis 1995). This takes the form of a continuous rotation going from northeasterly at the beginning of the year to southeasterly in July and August before returning to its initial direction in the second half of the year.

Along with distance from the coast, the other factor that plays an important role in salt loss is moisture. In French Guiana, humidity at low atmospheric levels remains almost constant (around 95\%) throughout the year and there is consequently not much crystallization in the lowest layers. Therefore, dry deposition is not a predominant factor in this region and will not be investigated directly in our study.
To determine the marine chlorine background, the French Guiana Space Center sponsored two measurement procedures on atmospheric chloride deposition between 2004 and 2008 in the Sinnamary coastal plain. This study concentrates on the presence of natural chloride in coastal French Guiana. Deposition data from the Observatoire Regional de l'Air (ORA) are available for 2004-08. In this study, a total deposition method is used to assess the background level of chlorine in the French Guiana basin coastal atmosphere. To obtain the chloride background, we perform a data analysis of the mean deposition values. The effect of distance from the sea on the marine salt data is then observed. A parametric equation to represent the behavior of each model parameter is proposed for the studied region. Finally, the sea salt deposition is compared with that of a neighboring region, Brazil (Meira et al. 2006, 2007), to provide an overview of ITCZ interaction and its impact on natural background.

Because the observation sites in French Guiana are distributed more than $12 \mathrm{~km}$ from the shore, we also consider another model (Hossain and Easa 2011). In a recent study, in the Cape peninsula in South Africa, Alao (2015) proposed three exposure zones for the impact of an airborne chloride attack. The first one was from the shore to $3 \mathrm{~km}$, the second between 3 and $14 \mathrm{~km}$, which corresponds to our studied area, and the last one more than $14 \mathrm{~km}$ from the shore. In a study on airborne chloride and corrosion performed in Spain (Alcántara et al. 2015), an exponential relationship between deposition and distance to shore was proposed.

\section{Experiments, measurement sites, and schedule}

Based on the position of the launchpad site in French Guiana, the experimental program involved 10 sampling stations in the Sinnamary area. Sinnamary is located next to the coast of French Guiana and extends inland. It is a small town with a very low population density (three inhabitants per square kilometer), whose main activities are small-scale fishing and agriculture. Air pollution is very low in terms of $\mathrm{NO}_{x}$ and $\mathrm{SO}_{2}$ concentrations (ORA measurement reports).

Figure 1 shows the site locations, where chloride concentrations were collected. The different sites were designated and identified by their distance from the coastal line, varying from $400 \mathrm{~m}$ to $14 \mathrm{~km}$. The sites were selected based on criteria such as availability of an open area with cover and absence of interference from objects (e.g., trees). The 10 sites are located along Sinnamary's river, from point A (located at the river mouth close to the shore) to the most distant point J. Some points, due to their proximity, can be considered as duplicates $(\mathrm{B}-\mathrm{C}$, 

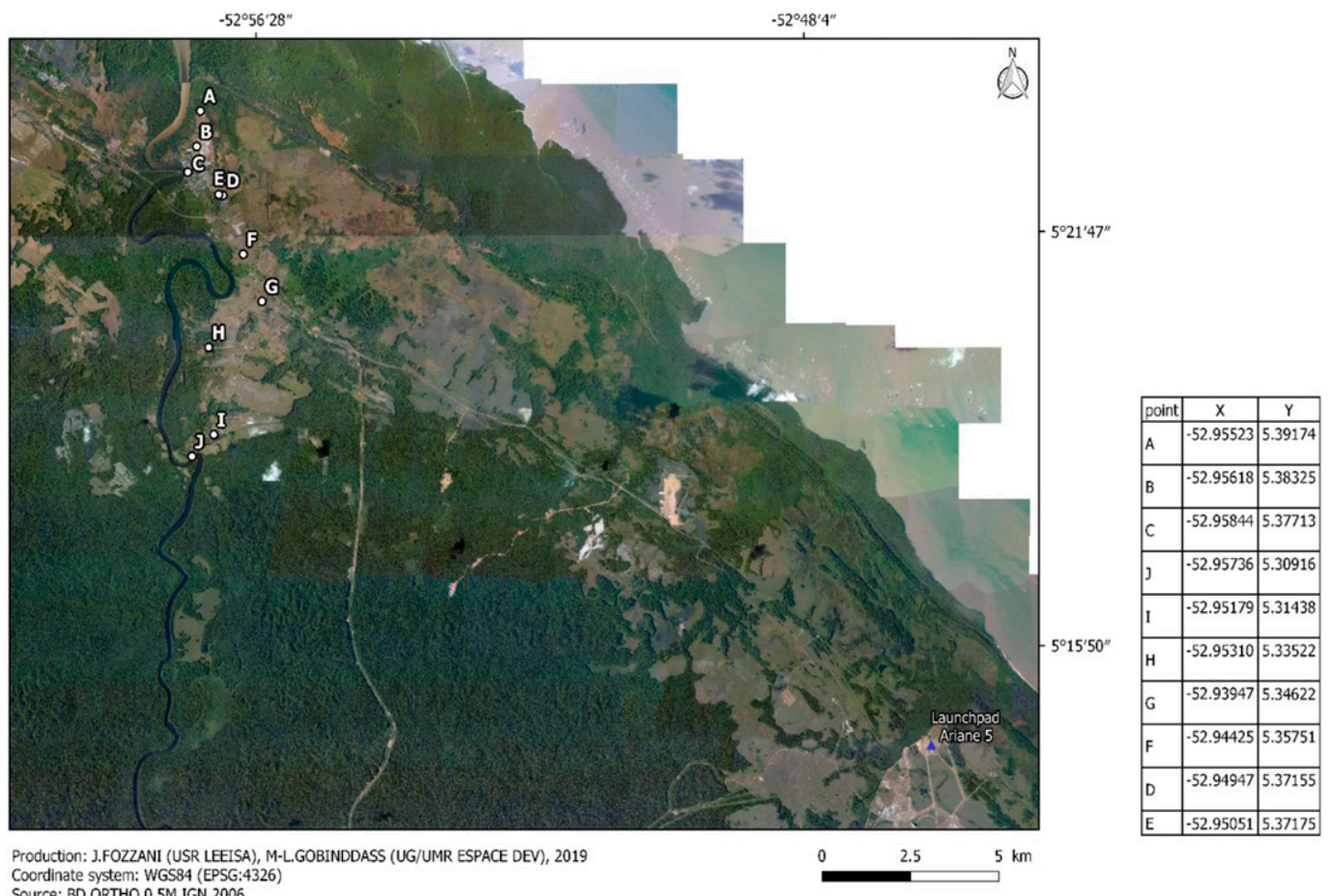

FIG. 1. Map of the Sinnamary area with the locations of the field measurement sites and Ariane V's launchpad location.

$\mathrm{F}-\mathrm{G}$, and $\mathrm{I}-\mathrm{J})$. The main goal of this study is to determine the chlorine background in order to measure the impact of space activity on the environment. The aim is to verify whether the equation proposed in previous works can be applied to any point on the Guyana basin coast.

\section{Data}

\section{a. Material and analysis}

At each site, the sampling of atmospheric deposition was performed using a water tank, which allows the collection of chloride ions in particulate form or dissolved in precipitation. To start with, the tank contains $300 \mathrm{~mL}$ of distilled water. It is then exposed continuously for several days; in most cases the sample exposure durations were close to seven days. For all sites during a given exposure week, the distilled water comes from the same tank, and after installation of all the measurement points, a blank sample is collected and indexed.

\section{b. Deposition data}

After one week of exposure, the water is abstracted from the tank (shown in Fig. 2) and replaced with $300 \mathrm{~mL}$ of distilled water. For every exposed water tank sample, the time exposure duration and the water tank volume at the end were noted. The exposed waters were analyzed using ionic chromatography to obtain the $\mathrm{Cl}^{-}$ concentration. Using the surface area of the opening $\left(6.4 \mathrm{~cm}^{2}\right)$, we can compute for each point the mean deposition concentration during exposure time $T$ :

$$
C_{s}=\frac{C_{p} V}{S T}
$$

where $C_{s}$ is the deposition rate $\left(\mathrm{mg} \mathrm{m}^{-2}\right.$ day $\left.^{-1}\right)$ during the period $T, S$ is the exposed surface area of the apparatus $\left(6.4 \mathrm{~cm}^{2}\right), T$ is the exposure time (days), $V$ is the volume of water $(\mathrm{L})$ found in the tank after exposure and $C_{p}$ is the concentration of chloride in the exposed

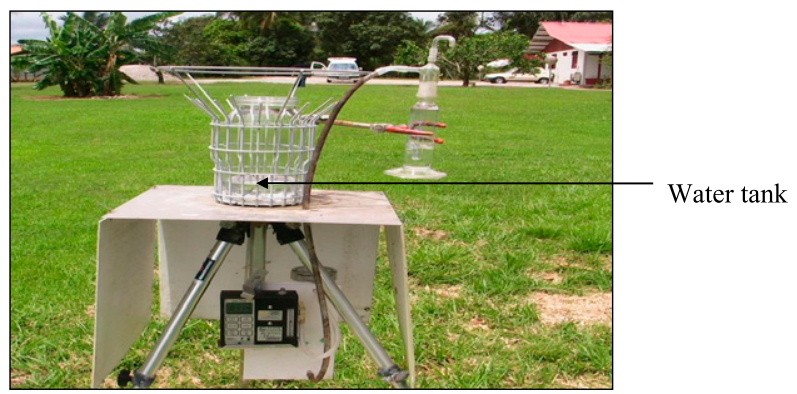

FIG. 2. Global deposition apparatus. 
TABLE 1. Number of deposition values from 2004 to 2008.

\begin{tabular}{lrrrrrrrrrr}
\hline & \multicolumn{10}{c}{ Sites } \\
\cline { 2 - 11 } \multicolumn{1}{c}{ Months } & \multicolumn{1}{c}{ A } & B & C & \multicolumn{1}{c}{ D } & E & F & G & H & I & J \\
\hline January & 13 & 13 & 17 & 15 & 16 & 14 & 17 & 14 & 17 & 13 \\
February & 15 & 16 & 16 & 15 & 16 & 16 & 16 & 16 & 16 & 16 \\
March & 15 & 15 & 15 & 15 & 15 & 16 & 16 & 16 & 16 & 16 \\
April & 13 & 15 & 17 & 16 & 16 & 14 & 16 & 15 & 18 & 15 \\
May & 15 & 16 & 17 & 17 & 17 & 15 & 16 & 16 & 17 & 16 \\
June & 16 & 16 & 18 & 17 & 18 & 16 & 18 & 16 & 18 & 16 \\
July & 14 & 15 & 18 & 18 & 16 & 14 & 18 & 15 & 18 & 15 \\
August & 19 & 19 & 20 & 21 & 21 & 20 & 22 & 20 & 22 & 19 \\
September & 11 & 14 & 10 & 10 & 12 & 14 & 14 & 14 & 13 & 14 \\
October & 6 & 16 & 14 & 12 & 12 & 14 & 14 & 13 & 14 & 14 \\
November & 8 & 16 & 16 & 11 & 12 & 16 & 16 & 16 & 16 & 16 \\
December & 9 & 13 & 15 & 13 & 13 & 13 & 14 & 13 & 15 & 13 \\
Total & 154 & 184 & 193 & 180 & 184 & 182 & 197 & 184 & 200 & 183 \\
\hline
\end{tabular}

water, which was provided by the French Guiana Pasteur Institute $\left(\mathrm{mg} \mathrm{L}^{-1}\right.$; detection threshold $\left.0.05 \mathrm{mg} \mathrm{L}^{-1}\right)$.

It should be noted that the chloride deposition refers to chlorides deposited on a retaining device, while the marine aerosol is transported inland by the wind. In this work, the total chloride deposition rate was measured at 10 monitoring stations placed at a few sites. The number of chloride deposition values at the sites remains relatively constant and is substantially uniform over 1 month (Table 1).

Data were missing for some weeks. Indeed, when leaves, grass or other vegetation have been found in the water, the deposition was not calculated. However, there is enough to perform a climatologic study.

\section{Results and discussion}

\section{a. Deposition results}

From Fig. 3a, concentrations at all the sites show similar behavior for the 3 years. Two distinct periods can be identified, one with high deposition values, beginning around the last month of each year and ending at the first month of the spring, and followed by a low-concentration period. The maximum value of $269 \mathrm{mg} \mathrm{m}^{-2}$ day $^{-1}$ was observed at site $\mathrm{J}$ in March 2006. The minimum values correspond to the limit of detection using this method, $0.15 \mathrm{mg} \mathrm{m}^{-2} \mathrm{day}^{-1}$. From June to October for each of the 3 years a season of low atmospheric sea salt chloride concentration is observed, whereas from December to April a season of high sea salt chloride concentration occurs. The two transition months correspond to the ITCZ crossing over French Guiana.

The average concentrations at all the sites presented in Table 2 have values between 15.7 and $23.7 \mathrm{mg} \mathrm{m}^{-2}$ day $^{-1}$. These values are within the range of concentrations found
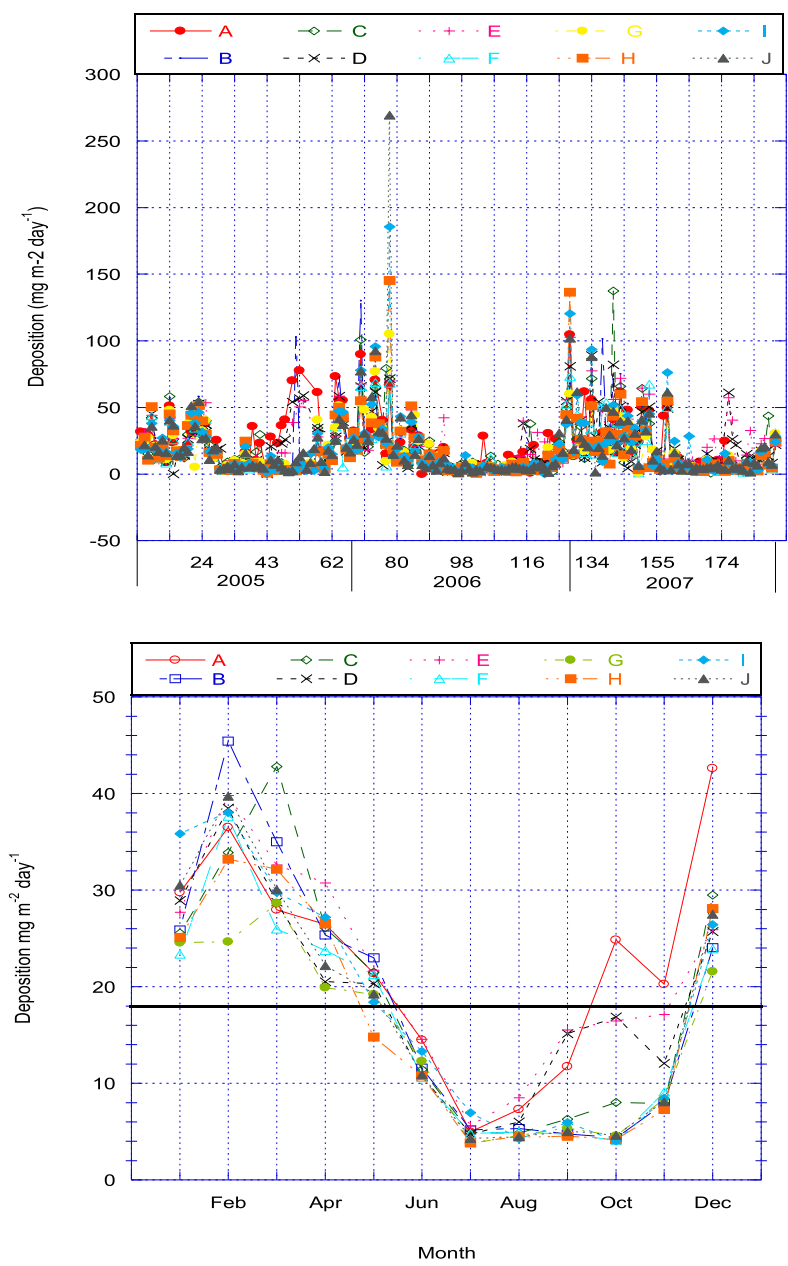

FIG. 3. (a) Chloride deposition values from 2005 to 2007. (b) Monthly mean chloride deposition.

by Meira et al. (2003), at a distance to shore less than $1 \mathrm{~km}$, and Forti et al. (2000), $80 \mathrm{~km}$ inland, in the northeastern part of tropical South America.

Figure $3 \mathrm{~b}$ presents the monthly averages for 2 years (2006 and 2007). We clearly observe a low and a high season in atmospheric chlorine with, respectively, low mean chloride deposition values (LC) and high mean chloride deposition values (HC). This annual oscillation could be guided by the ITCZ, which controls the characteristics of the atmosphere seasonally by modulating the main meteorological parameters (pressure, temperature, direction and intensity of the wind, precipitation).

Considering all the observations made from Figs. 3a and $3 b$, the rainfall associated with the passage of the ITCZ does not seem to be the major factor for deposition during the high chlorine season. The season locally called "the small summer of March" seems to correspond with higher sea salt chlorine presence, and the dry 
TABLE 2. Site deposition statistics.

\begin{tabular}{lrrrrrrrrrr}
\hline & \multicolumn{10}{c}{ Sites } \\
\cline { 2 - 10 } & A & B & \multicolumn{1}{c}{ C } & D & E & F & G & H & I & J \\
\hline Mean & 23.69 & 17.8 & 18.07 & 20.87 & 21.95 & 15.66 & 15.76 & 16.22 & 17.268 & 17.09 \\
Median & 20.94 & 14.31 & 14.53 & 17.56 & 19.32 & 13.39 & 13.08 & 12.06 & 12.735 & 13.11 \\
Standard deviation & 15.63 & 13.57 & 13.29 & 13.71 & 12.94 & 11.13 & 11.48 & 13.11 & 13.49 & 13.20 \\
Standard error & 2.72 & 2.26 & 2.21 & 2.28 & 2.16 & 1.85 & 1.913 & 2.18 & 2.249 & 2.20 \\
\hline
\end{tabular}

season from June to October with low chlorine contents. Thus, despite the important role played by rain in aerosol washout, it is not the predominant parameter driving the sea salt deposition.

Following the numerous studies relating sea salt deposition and wind, the chlorine deposition behavior is analyzed considering wind parameters, in the following.

\section{b. Sea salt chlorine and wind speed}

Using the National Centers for Environmental Prediction (NCEP) reanalysis model, mean wind behavior during two periods has been calculated for this area. Figure $4 \mathrm{a}$ presents a composite mean wind at $1000 \mathrm{hPa}$ during the high sea salt chlorine season (December to April) for 2005 to 2007, and Fig. 4b presents the mean wind during the low sea salt chlorine season (June to October). It appears that the high chlorine season has wind speed values between 6 and $7 \mathrm{~m} \mathrm{~s}^{-1}$ close to the French Guiana coast, and low sea salt corresponds with wind speeds between 4 and $5 \mathrm{~m} \mathrm{~s}^{-1}$.
Using these wind intensity values and Eq. (1), which provides sea salt concentration as a function of wind speed, and with the hypothesis that both parameters $(a, b)$ remain unchanged throughout the year in a given area of ocean, we can calculate the sea salt production variation. The ratio of $\mathrm{HC}$ concentration to $\mathrm{LC}$ concentration,

$$
R_{\mathrm{HC} / \mathrm{LC}}=\frac{\mathrm{HC}}{\mathrm{LC}},
$$

is close to $e^{U_{\mathrm{HC}}-U_{\mathrm{LC}}}$, where $U_{\mathrm{HC}}$ is the wind speed during the high chlorine season and $U_{\mathrm{LC}}$ is the wind speed during the low chlorine season. Using the mean winds observed in NCEP data (Figs. 4a,b), the value of $R_{\mathrm{HC} / \mathrm{LC}}$ value is close to $e^{2}=7.4$.

On the other hand, the ratio obtained from the mean deposition during the high chlorine period $\left(29.27 \mathrm{mg} \mathrm{m}^{-2}\right)$ to that during the low chlorine period $\left(8.9 \mathrm{mg} \mathrm{m}^{-2}\right)$ is $R_{\mathrm{HC} / \mathrm{LC}}=29.27 / 8.9$, which is close to 3.3 , different from the value of 7.4 obtained in the previous
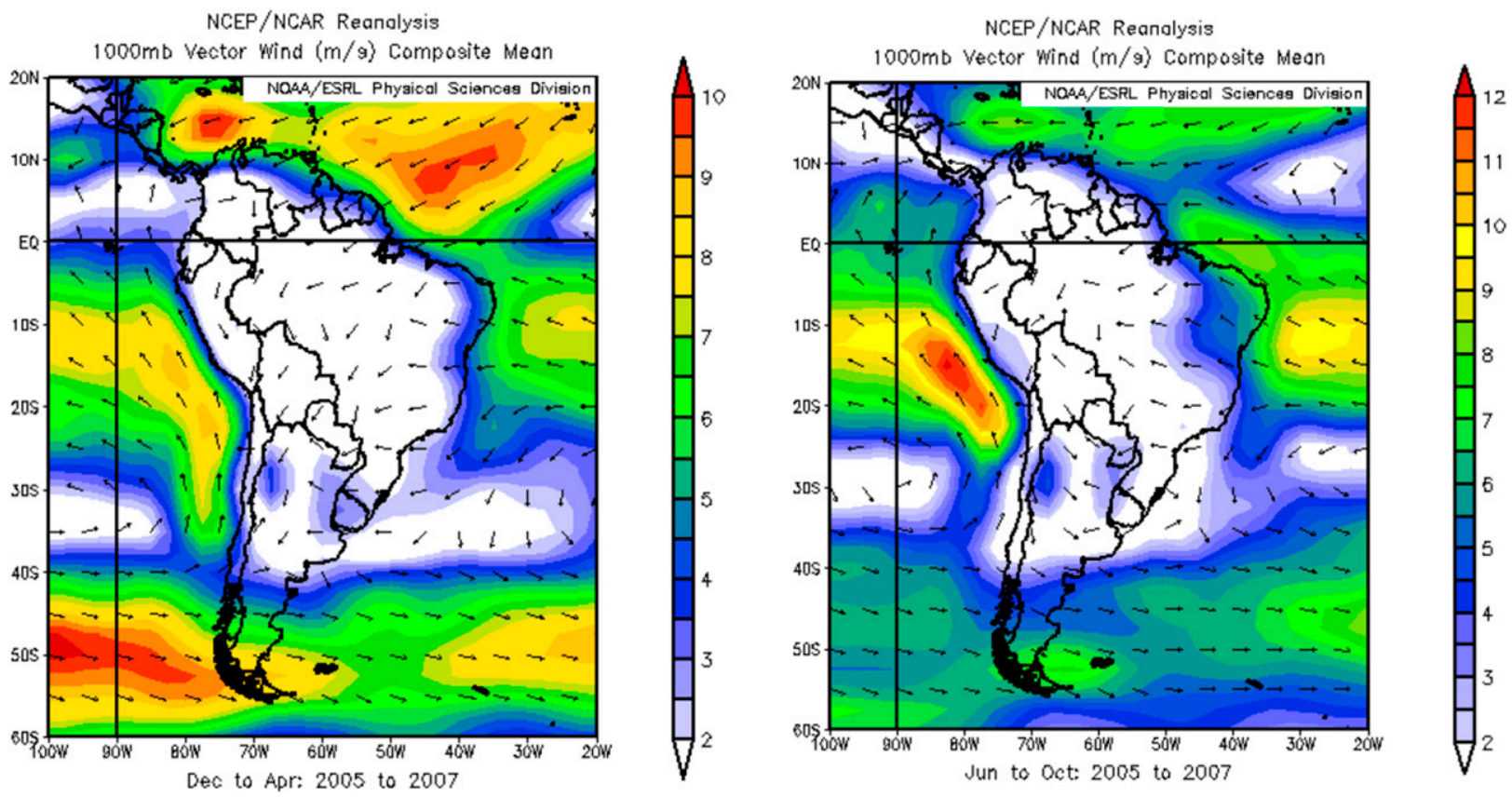

FIG. 4. (a) High sea salt season mean wind for 2005-07. (b) Low sea salt season mean wind for 2005-07. 


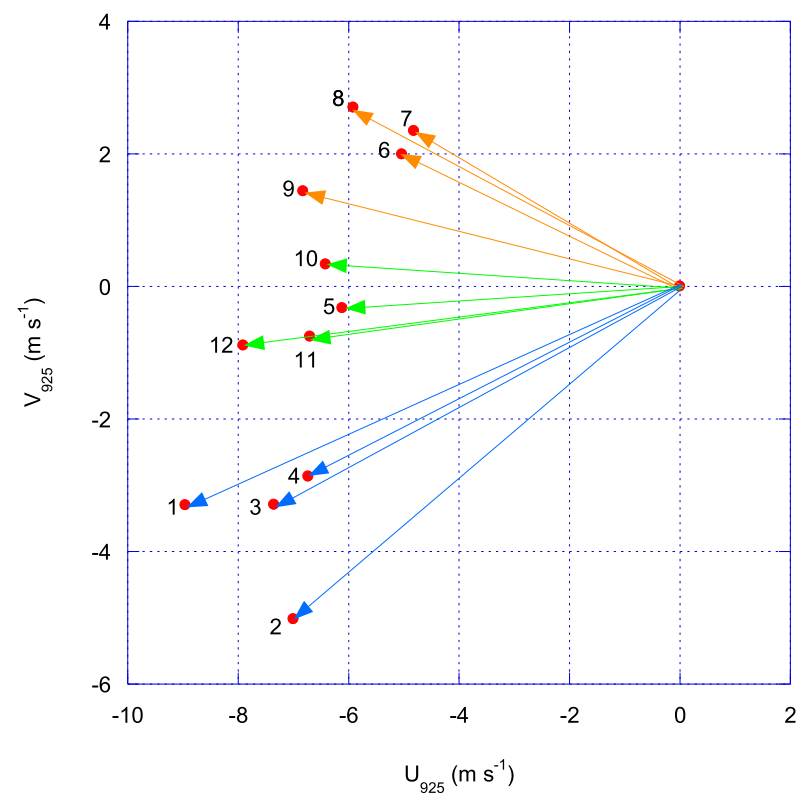

FIG. 5. Mean monthly wind at $950 \mathrm{hPa}$ calculated using soundings from 2006 and 2007 (the number indicates the month: January = 1; February $=2$, etc.).

paragraph. Relating sea salt chloride production to wind speed seems to explain less than half of the inland deposition behavior.

\section{c. Sea salt chlorine and wind direction}

In Figs. $4 \mathrm{a}$ and $4 \mathrm{~b}$ a rotation in wind direction can be observed. From December to April the mean wind direction is northeasterly and from June to October it is easterly. It is likely that this rotation in wind direction must be considered. From November to April, the meridional component of the trade winds is negative, coming from the north, so the air masses transported over French Guiana are mainly maritime. On the contrary, from June to October the meridional component of the wind comes from the South (Fig. 5), bringing to Guiana air masses with less maritime influence. This behavior also affects the number of storms observed during these periods (Molinié and Pontikis 1995).

An analysis of the deposition and wind data seems to show a correlation between these two elements. Indeed, over the year and under the influence of the position of the ITCZ, a rotation of the lower-layer winds is observed in Fig. 5, which corresponds with the variations in chlorine concentration. During the high chloride season, the wind is northeasterly, and the marine influence is higher because the distance from the sea is lower. On the other hand, during the low season of chloride the wind is southeasterly and the maritime air masses travel farther over land, causing a loss of salt, before reaching

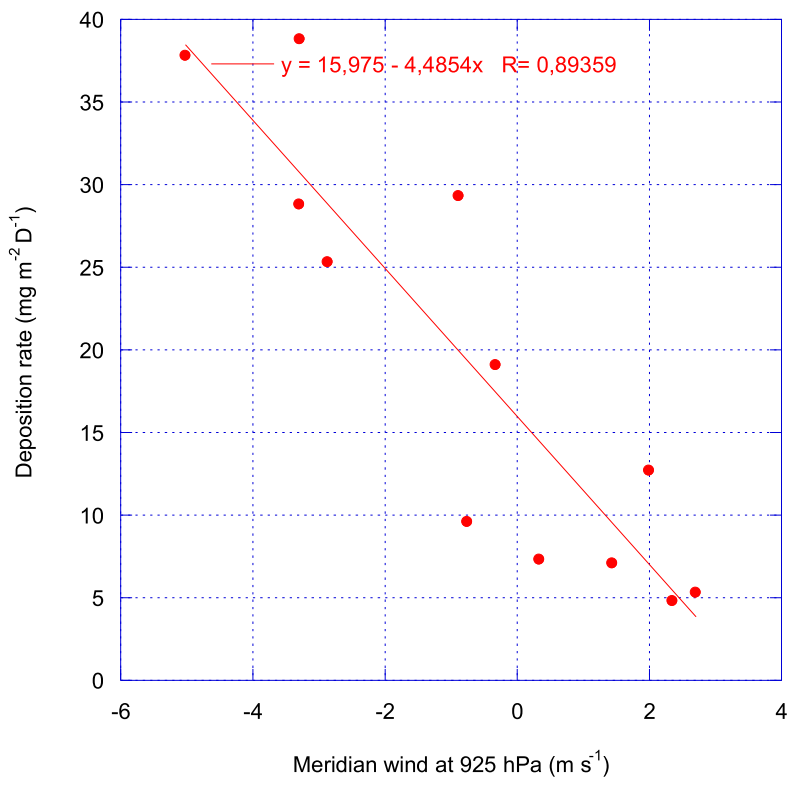

FIG. 6. Mean monthly chloride total deposition from 2006 to 2007 vs mean monthly meridian wind component at $925 \mathrm{hPa}$.

the different measurement sites. It appears from Fig. 5 that four months are characterized by a low meridional wind component. These can be termed transition months in wind direction because they are situated between the northerly influence from January to April and the southerly influence from June to September. The wind direction rotation observed between the high chloride season and low chloride season is close to $60^{\circ}$.

This behavior is confirmed by the relationship found between the monthly deposition rate and the monthly meridional wind component at $925 \mathrm{hPa}$, obtained from soundings performed in the vicinity of Cayenne. It can therefore be concluded that the ITCZ has an influence, through the wind speed and direction, on the amount of chlorine present in the French Guiana coastal atmosphere Fig. 6.

\section{d. Concentration variation with distance to sea}

\section{1) Total Deposition}

Figure 7 shows the mean and median concentrations obtained from the experiment sites as a function of the distance from the measuring point to the shore. Globally, a decrease for both deposition parameters with distance from the sea has been observed. However, the correlation coefficients with the exponential model and the power model, respectively, 0.62 and 0.70 for the mean values and 0.68 and 0.74 for the median values, do not allow us to validate this decreasing behavior with distance to shoreline. The amplitude of the oscillation 


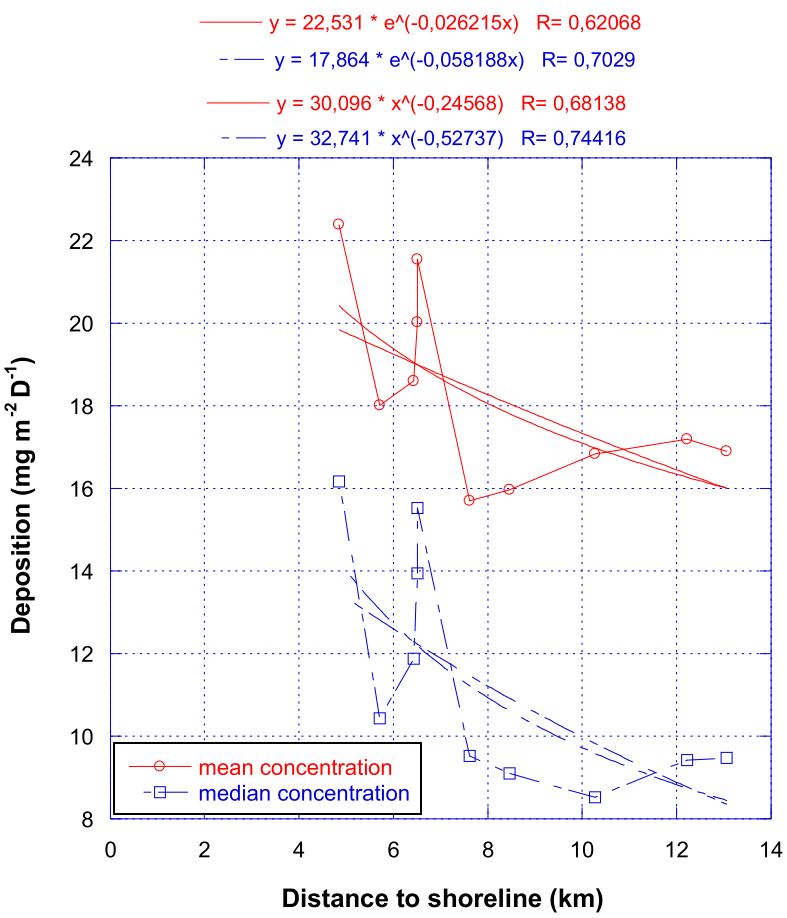

FIG. 7. Chloride concentration total deposition as a function of distance to shoreline from 2005 to 2007 (mean and median).

observed between 6 and $8 \mathrm{~km}$ can be attributed to the impact of washout on the total deposition. Due to the interaction of the sea-breeze flow with the coast, a quasipersistent cloud line is generated (Dahech et al. 2012). In our case, this manifest itself as a rainy microclimate at these distances.

The variation of salt concentration of marine aerosol with wind speed is typically represented by an exponential growth function (Lovett 1978; Kulkarni et al. 1982; Exton et al. 1985; Gustafsson and Franzén 1996; Wai and Tanner 2004). The sea salt source production can be considered to be the same for all the inland measuring points. The behavior of the sea salt chloride concentration can only be related to the distance from the shore and the interaction with the environment (trees, soils, buildings, etc.). In this area, the change in landscape patterns also itself depends on the distance to the sea. Moving inland from the shore, we first observe the presence of mangroves followed by salt marshes before man-made land and finally primary forest. For the dependence between the salt concentration and the distance to the sea, we use a relationship characterizing the deposition as an inverse power function of distance to the sea (Gustafsson and Franzén 1996; Meira et al. 2003; Corvo et al. 1995; Hossain and Easa 2011; Alao 2015):

$$
D=a X^{-b}=a e^{-b \ln (X)},
$$

where $D$ is the deposition and $X$ is the distance to the sea.

In another part of the world, Hossain and. Easa (2011) analyzed the variation of dry deposition of atmospheric salts that deposited on wet candle sensors during a 6-month sampling period in Bangladesh. The variation in concentration with distance from the sea, of atmospheric salts originating from sea spray (chlorides $\mathrm{Cl}^{-}$ and part of the sulfates $\mathrm{SO}_{4}^{2-}$ ) and from other sources [nitrates $\mathrm{NO}_{3}^{-}$and other sulfates $\mathrm{SO}_{4}^{2-}$ (other)], were considered. Regression equations were obtained with $a=4.478 \mathrm{mg} \mathrm{m}^{-2} \mathrm{day}^{-1}$ and $b=-0.744$.

Another expression is classically used with an exponential relationship to represent the chloride deposition decay with distance to shore (Feliu et al. 1999):

$$
D=C_{O} e^{-\beta x}
$$

where $D$ is the chloride deposition on a testing device, $x$ is the distance from the sea and $C_{O}$ and $\beta$ are two parameters dependent on the area and the wind speed.

Both relationships are fitted to the present data and represented in Fig. 7. From this, the correlation coefficient with the Hossain equation is better (mean: 0.68; median: 0.74 ) but the behavior also remains close to Meira's equation (mean: 0.62; median: 0.70 ).

Relationships based on Eq. (4) are mainly used at sites dominated by surf-produced aerosol (Exton et al. 1985; Gustafsson and Franzén 1996). This equation was also used by Meira et al. $(2003,2006)$ for the Brazilian coast.

\section{2) DRY DEPOSITION}

Regarding the ratio proposed by Erickson and Duce (1988) for regions under the influence of the ITCZ where wet deposition is equal to dry deposition over the ocean, we considered this assumption was applicable to the site closest to the sea (site A). The mean amount of chlorine brought by wet deposition is therefore half of the total chlorine here, and the mean concentration $\left(\left[\mathrm{Cl}^{-}\right] \mathrm{mL}^{-1}\right)$ added by precipitation has been calculated. We suggest that this concentration remains constant and, using the amount of water brought by precipitation, we calculate a dry deposition for the 10 sites. Figure 8 shows the correlation between this calculated mean dry deposition and distance to the sea. The correlation coefficients for the exponential and power expressions provide a similar result, around 0.9.

With the calculated dry deposition, we reduced the influence of the coastal frontal band precipitation, which plays an important role in the wet deposition in this area.

Table 3 presents some of the relationships proposed by studies carried out under different environments around the world. The empirical expression in Eq. (4) does not account for differences in generation source 


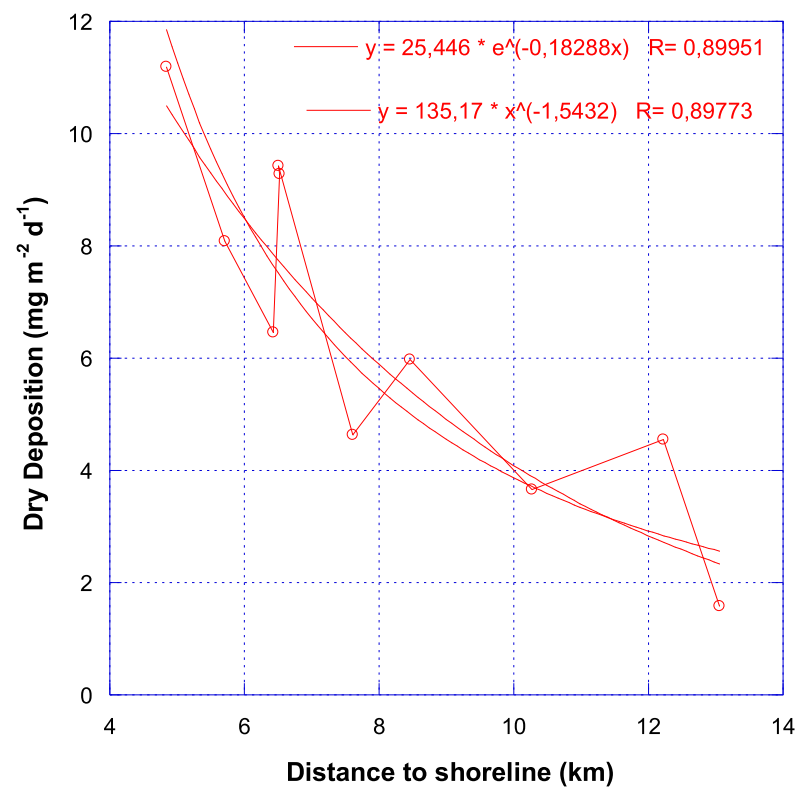

FIG. 8. Mean dry deposition vs distance to shoreline.

and transportation of marine aerosol when the distance to shoreline exceeded one kilometer. The decay constant of the power law per kilometer, during inland transport (1.54) found by regression in Fig. 8, can be used to calculate the loss during the wind rotation by assuming that the rotation induces an increase of the transport distance with a ratio of: $R_{\text {Cl_loss }}=1 / \cos$ (wind direction rotation). We found a ratio between $\mathrm{HC}$ and LC relating to wind rotation of $R_{\mathrm{Cl} \_ \text {loss }} \approx 2$.9. This result is close to the $R_{\mathrm{HC} / \mathrm{LC}}$ value obtained from mean concentrations, which is 3.3 , implying that the seasonality in chloride deposition for this area of South America largely depends on the wind rotation.

The relationships presented in Table 3 show significant variation in the function coefficients, probably implying an influence from wind direction on the parameters relating deposition with distance to sea.

\section{Conclusions}

From an analysis of French Guiana coastal total deposition measurements, a seasonal behavior of sea salt chlorine has been found. Along the months, a cycle with high concentrations of chloride from December to April and low concentrations from June to October, has been observed.

The sea salt production and loss conditions in our equatorial coastal region vary throughout the year due to low-level wind speed, contributing to a seasonality in sea salt chlorine deposition. This relationship can explain only half of the deposition behavior; the other half is related to ITCZ position, due to the huge inflow of freshwater to the sea during the rainy season.

A correlation between wind directions and chloride deposition has been found, suggesting a potential role of the path of maritime air masses over land. Higher sea salt chlorine deposition periods correspond with trajectories passing shorter distances over land and, inversely, lower deposition with longer distances over land.

Moreover, the seasonal dependence of the exponential and power equations linking the mean total deposition with distance from the sea have been studied. Both

TABLE 3. Comparison of chlorine deposition and distance to shoreline $(\mathrm{km})$, as calculated for different regions.

\begin{tabular}{|c|c|c|c|c|c|}
\hline Reference & $\begin{array}{l}\text { Marine environment } \\
\text { country }\end{array}$ & $\begin{array}{l}\text { Distance from } \\
\text { the sea }(\mathrm{m})\end{array}$ & $\begin{array}{l}\text { Salt deposition } \\
\left(\mathrm{mg} \mathrm{m}^{-2} \text { day }^{-1}\right)\end{array}$ & Equation & Apparatus \\
\hline Corvo et al. (1995) & $\begin{array}{l}\text { Atlantic Ocean } \\
\text { Cuba }\end{array}$ & $1-1100$ & $525-19.5$ & & Dry plate \\
\hline Feliu et al. (1999) & $\begin{array}{l}\text { Nigeria } \\
\text { Cuba } \\
\text { Brazil } \\
\text { India }\end{array}$ & $0-600$ & & $\begin{array}{l}D=24.63 \times 10^{-6.3 x} \\
D=28.6 \times 10^{-10.4 x} \\
D=11.3 \times 10^{-3.5 x} \\
D=9.06 \times 10^{-4.9 x}\end{array}$ & \\
\hline Meira et al. (2003) & $\begin{array}{l}\text { Atlantic Ocean } \\
\text { Brazil }\end{array}$ & $10-1100$ & $460-6$ & {$\left[\mathrm{Cl}^{-}\right]=6.17 X^{-0.957}$} & Wet candle \\
\hline Hossain and Easa (2011) & Indian Ocean & $93-7012$ & $54.02-1.31$ & {$\left[\mathrm{Cl}^{-}\right]=4.478 X^{-0.744}$} & Wet candle \\
\hline Alao (2015) & $\begin{array}{l}\text { Atlantic Ocean } \\
\text { South Africa }\end{array}$ & $50-13550$ & $138.1-11.8$ & $\begin{aligned} D & =41.77 \times 10^{-0.11 x} \\
{\left[\mathrm{Cl}^{-}\right] } & =23.69 X^{-0.392}\end{aligned}$ & Wet candle \\
\hline Alcántara et al. (2015) & Spain & $300-2500$ & 1905.5-11.6 & $\begin{aligned} D & =1054.8 \times 10^{-1.32 x} \\
{\left[\mathrm{Cl}^{-}\right] } & =195.63 X^{-1.558}\end{aligned}$ & Wet candle \\
\hline Our measures (2005-07) & $\begin{array}{l}\text { Atlantic Ocean } \\
\text { French Guiana }\end{array}$ & $4000-13000$ & $22.4-15.7$ & $\begin{aligned} D & =22.531 \times 10^{-0.0263 x} \\
{\left[\mathrm{Cl}^{-}\right] } & =32.741 X^{-0.527}\end{aligned}$ & Total deposition \\
\hline Calculated dry deposition & $\begin{array}{l}\text { Atlantic Ocean } \\
\text { French Guiana }\end{array}$ & $4000-13000$ & $11.2-1.6$ & $\begin{aligned} D & =25.446 \times 10^{-0.1829 x} \\
{\left[\mathrm{Cl}^{-}\right] } & =136.2 X^{-1.543}\end{aligned}$ & Dry deposition \\
\hline
\end{tabular}


equations showed poorer correlation coefficients due to the impact of the washout by local rainy coastal clouds. A hypothesis using the wet and dry deposition ratio allowed us to calculate the mean dry sea salt deposition, which has been correlated with distance to the sea and leads to better correlation coefficients.

Loss of chlorine by deposition was better described with a power-law model for distances to shoreline higher than $1 \mathrm{~km}$.

We found that the difference between the high chloride deposition season and low chloride deposition season is mainly related to the wind direction rotation, which is a consequence of the ITCZ cycle. It would be interesting to verify that this seasonal behavior, related to the ITCZ passage, concerns the rest of the tropical band of the South America continent between French Guiana and Venezuela, with a focus on the relationship between large river input of freshwater on salinity and sea salt deposition. It will also be appropriate to check the validity of the equations we found in the rest of the Guiana basin.

The chlorine impact of rocket launch, more visible in chloride concentration in air will be our next goal.

\section{REFERENCES}

Alao, O., 2015: Refinement of air-borne chloride exposure classes for RC structures in the Cape Peninsula. M.S. thesis, Dept. of Civil Engineering, University of Cape Town, 145 pp., http:// hdl.handle.net/11427/13644.

Alcántara, J., B. Chico, I. Díaz, D. de la Fuente, and M. Morcillo, 2015: Airborne chloride deposit and its effect on marine atmospheric corrosion of mild steel. Corros. Sci., 97, 74-88, https://doi.org/10.1016/j.corsci.2015.04.015.

Ambler, H. R., and A. A. J. Bain, 1955: Corrosion of metals in the tropics. J. Appl. Chem., 5, 437-467, https://doi.org/10.1002/ JCTB.5010050901.

Andreae, M. O., R. J. Charlson, F. Bruynseels, H. Storms, R. Van Grieken, and W. Maenhaut, 1986: Internal mixture of sea salt, silicates, and excess sulfate in marine aerosols. Science, $\mathbf{2 3 2}$, 1620-1623, https://doi.org/10.1126/science.232.4758.1620.

Corvo, F., N. Betancourt, and A. Mendoza, 1995: The influence of airborne salinity on the atmospheric corrosion of steel. Corros. Sci., 37, 1889-1901, https://doi.org/10.1016/0010-938X(95)00058-R.

Dahech, S., J.-C. Berges, and G. Beltrando, 2012: Localisation et dynamique du front de la brise de mer au Maghreb oriental. Climatologie, 9, 59-81, https://doi.org/10.4267/climatologie.189.

de Leeuw, G., E. L. Andreas, M. D. Anguelova, C. W. Fairall, E. R. Lewis, C. O'Dowd, M. Schulz, and S. E. Schwartz, 2011: Production flux of sea spray aerosol. Rev. Geophys., 49, RG2001, https://doi.org/10.1029/2010RG000349.

Erickson, D., III, and R. Duce, 1988: On the global flux of atmospheric sea salt. J. Geophys. Res., 93, $14079-14088$, https:// doi.org/10.1029/JC093iC11p14079.

Exton, H. J., J. Latham, P. M. Park, S. J. Perry, M. H. Smith, and R. R. Allan, 1985: The production and dispersal of marine aerosol. Quart. J. Roy. Meteor. Soc., 111, 817-837, https:// doi.org/10.1002/qj.49711146509.
Feliu, S., M. Morcillo, and B. Chico, 1999: Effect of distance from sea on atmospheric corrosion rate. Corrosion, 55, 883-891, https://doi.org/10.5006/1.3284045.

Forti, M. C., A. J. Melfi, R. Astolfo, and A.-H. Fostier, 2000: Rainfall chemistry composition in two ecosystems in the northeastern Brazilian Amazon (Amapá State). J. Geophys. Res., 105, 28 895-28 905, https://doi.org/10.1029/2000JD900235.

Gong, S. L., 2003: A parameterization of sea-salt aerosol source function for sub- and super-micron particles. Global Biogeochem. Cycles, 17, 1097, https://doi.org/10.1029/2003GB002079.

Gustafsson, M. E. R., and L. G. Franzén, 1996: Dry deposition and concentration of marine aerosols in a coastal area, SW Sweden. Atmos. Environ., 30, 977-989, https://doi.org/10.1016/ 1352-2310(95)00355-X.

Héritier, P., 2011: Le Climat Guyanais: Petit Atlas Climatique de la Guyane Francaise. Météo France, 56 pp.

Hossain, K. and S. Easa, 2011: Spatial distribution of marine salts in coastal region using wet candle sensors. Int. J. Res. Rev. Appl. Sci., 7, 228-235.

Kulkarni, M. R., B. B. Adiga, R. K. Kapoor, and V. V. Shirvaikar, 1982: Sea salt in coastal air and its deposition on porcelain insulators. J. Appl. Meteor., 21, 350-355, https://doi.org/10.1175/ 1520-0450(1982)021<0350:SSICAA > 2.0.CO;2.

Lovett, R. F., 1978: Quantitative measurement of airborne sea-salt in the North Atlantic. Tellus, 30, 358-364, https://doi.org/ 10.3402/tellusa.v30i4.10354.

McDonald, R. L., C. K. Unni, and R. A. Duce, 1982: Estimation of atmospheric sea salt dry deposition: Wind speed and particle size dependence. J. Geophys. Res., 87, 1246-1250, https:// doi.org/10.1029/JC087iC02p01246.

Meira, G. R., I. J. Padaratz, C. Alonso, and C. Andrade, 2003: Effect of distance from sea on chloride aggressiveness in concrete structures in Brazilian coastal site. Mater. Constr., 53, 179-188.

- M. C. Andrade, I. J. Padaratz, M. C. Alonso, and J. C. Borba, 2006: Measurements and modelling of marine salt transportation and deposition in a tropical region in Brazil. Atmos. Environ., 40, 5596-5607, https://doi.org/10.1016/ j.atmosenv.2006.04.053

, — - C. Alonso, I. J. Padaratz, and J. C. Borba, 2007: Salinity of marine aerosols in a Brazilian coastal area-Influence of wind regime. Atmos. Environ., 41, 8431-8441, https://doi.org/ 10.1016/j.atmosenv.2007.07.004

Molinié, J., and C. A. Pontikis, 1995: A climatological study of tropical thunderstorm clouds and lightning frequencies on the French Guyana Coast. Geophys. Res. Lett., 22, 1085-1088, https://doi.org/10.1029/95GL01036.

Monahan, E. C., C. W. Fairall, K. L. Davidson, and P. J. Boyle, 1983: Observed inter-relations between $10 \mathrm{~m}$ winds, ocean whitecaps and marine aerosols. Quart. J. Roy. Meteor. Soc., 109, 379-392, https://doi.org/10.1002/qj.49710946010.

Pruppacher, H. R., and J. D. Klett, 1980: Microphysics of clouds and precipitation. Nature, 284, 88, https://doi.org/10.1038/ 284088b0.

Tsunogai, S., 1975: Sea salt particles transported to the land. Tellus, 27, 51-58, https://doi.org/10.3402/tellusa.v27i1.9883.

Vignati, E., and Coauthors, 2010: Global scale emission and distribution of sea-spray aerosol: Sea-salt and organic enrichment. Atmos. Environ., 44, 670-677, https://doi.org/10.1016/ j.atmosenv.2009.11.013.

Wai, K. M., and P. A. Tanner, 2004: Wind-dependent sea salt aerosol in a western Pacific coastal area. Atmos. Environ., 38, 1167-1171, https://doi.org/10.1016/j.atmosenv.2003.11.007. 